Jurnal Teknik Hidro

Vol. 11 No. 1, Februari 2018

\title{
ANALISIS REMBESAN PADA BENDUNGAN TIPE URUGAN (UJI SIMULASI LAB)
}

\author{
Nurnawaty $^{1)}$ Suhardiman $^{2)}$ dan Ihwan ${ }^{3)}$ \\ 1) Universitas Muhammadiyah Makassar, Indonesia \\ Email:nurnadzar@yahoo.com \\ ${ }^{2)}$ Universitas Muhammadiyah Makassar, Indonesia \\ Email : suhardiman@gmail.com \\ ${ }^{3)}$ Universitas Muhammadiyah Makassar, Indonesia \\ Email:ihwan@gmail.com
}

\begin{abstract}
ABSTRAK
Bendungan adalah sebuah struktur konstruksi yang dibangun untuk menahan laju air dari sisi hulu ke hilir. Salah satu masalah pada bendungan adalah rembesan. Rembesan didefenisikan sebagai sifat bahan berpori yang memungkinkan cairan yang berupa air atau minyak mengalir melewati rongga pori. Tujuan dari penelitian ini adalah untuk mengetahui pengaruh variasi tinggi hidrostatis terhadap rembesan yang terjadi pada tubuh bendungan. Material pembentuk tubuh bendungan adalah jenis tanah lempung organik. Penelitian ini meninjau pola rembesan dan debit rembesan terhadap variasi tinggi hidrostatis. Debit rembesan $\left(Q_{f}\right)$ dihitung menggunakan 3 metode yaitu metode Dupuit, metode Schaffernak, dan metode Cassagrande. Variasi tinggi hidrostatis yang ditinjau adalah $H_{10}, H_{15}$, dan $H_{20}$. Pada metode Cassagrande memperlihatkan debit yang tertinggi untuk $H_{10}$ dan $H_{15}$, pola rembesan yang terjadi tidak signifikan, karena waktu rembesannya sangat lambat, akibatnya debit rembesan yang dihasilkan pun sangat kecil. Sedangkan pada tinggi hidrostatis $\mathrm{H}_{20}$ metode Schaffernak memperlihatkan debit yang tertinggi. Berbeda dengan variasi tinggi $\mathrm{H}_{20}$ pola rembesan yang terjadi sangat signifikan, Karena waktu rembesannya sangat cepat, akibatnya debit rembesan yang dihasilkan pun sangat besar.
\end{abstract}

Kata kunci : Rembesan, Tinggi Hidrostatis, Bendungan Urugan

\begin{abstract}
Dam is a construction structure built to withstand water rates from upstream to downstream. One of the problems with the dam is the seepage. The permeability is defined as the nature of the porous material that allows liquid in the form of water or oil to flow through the pore cavity. The purpose of this study is to determine the effect of hydrostatic high variation on seepage that occurs in dam body. The body building material of the dam is a type of organic clay soil. This study looks at seepage patterns and seepage discharge against high hydrostatic variations. The seepage discharge $(Q f)$ is calculated using 3 methods of Dupuit method, Schaffernak method, and Cassagrande method. The hydrostatic high variations studied were H1O, H15, and H2O. In the Cassagrande method showing the highest discharge for H1O and H15, the seepage pattern is not significant, because the seepage time is very slow, resulting in the resulting seepage discharge is very small. While on hydrostatic high H2O Schaffernak method showed the highest discharge. In contrast to the high variation of H2O seepage pattern that occurs very significant, Because the time of seepage is very fast, resulting in the resulting seepage discharge is very large.
\end{abstract}

Keywords: Seepage, Hydrostatic Height, Urugan Dam 


\section{PENDAHULUAN}

Salah satu masalah yang sering terjadi pada bendungan adalah rembesan pada tubuh bendungan, rembesan merupakan aliran air yang secara terus menerus mengalir dari sisi hulu menuju sisi hilir, aliran air ini merupakan aliran dari air sungai, danau atau waduk melalui material yang lolos air (permeable), baik melalui tubuh bendungan maupun pondasi.

Untuk itu, dalam pembuatan bendungan terutama tipe urugan diperlukan syarat teknis, pertama pemilihan jenis tanah timbunan yaitu tanah yang ukuran porinya lebih kecil agar supaya stabilitas pada tubuh bendungan tidak terlalu besar, dan kedua kepadatan tanah yaitu kepadatannya harus lebih maksimal agar di dalam rongga pori tidak mudah lolos air yang akan bisa menimbulkan piping.

Pada penelitian ini penulis melaksanakan uji simulasi dengan ukuran, skala yang ditetapkan dan sesuai dengan kapasitas alat di Laborartorium Fakultas Teknik. Sebagaimana kita rencanakan dimensi ukuran model bendungan ini mempunyai ukuran lebar puncak yaitu $5 \mathrm{~cm}$, tinggi $28 \mathrm{~cm}$, serta lebar bawah $72 \mathrm{~cm}$ dan kemirinan 1:1,2 $\mathrm{cm}$.

Tujuan dari penelitian ini adalah untuk mengetahui pengaruh tinggi tekanan hidrostatis yang bervariasi terhadap rembesan yang terjadi pada tubuh bendungan. Dan mengetahui pola rembesan pada bendungan dengan tinggi tekanan hidrostatis yang bervariasi.

\section{Bendungan Urugan}

Menurut Asiyanto (2011), Bendungan atau dam adalah sebuah struktur konstruksi yang dibangun untuk menahan laju air atau sungai bawah tanah yang pada umumnya akan menjadi waduk atau danau artificial. Bendungan pada umumnya memiliki tujuan utama untuk menahan air tetapi juga memiliki bagian yang disebut pintu air atau tanggul yang digunakan untuk mengelola, mencegah atau membuang aliran air ke daerah lain, secara bertahap atau berkelanjutan. Dalam pembangunan bendungan baik itu bendungan urugan maupun bendungan beton, seringkali juga digunakan untuk mengalirkan air ke 
sebuah Pembangkit Listrik Tenaga Air atau PLTA

\section{Klasifikasi Tanah}

Menurut Hardiyatmo HC (2012), dalam Buku Darwis (2013), Klasifikasi tanah sangat membantu perancangan dalam menentukan metode rancangan yang dipergunakan, melalui cara empiris yang tersedia dari hasil-hasil pengalaman terdahulu. Akan tetapi perancangan harus tetap berhati hati dalam penerapannya karena penyelesaian masalah-masalah yang didasarkan pada klasifikasi tanah, sering kali memberikan hasil yang tidak tepat, terutama dalam hal perhitungan penurunan (kompressi).

\section{Pengertian Rembesan}

Menurut Hardiyatmo HC (2012), Permebilitas atau rembesan didefenisikan sebagai sifat bahan berpori yang memungkinkan aliran rembesan dari cairan yang berupa air atau minyak mengalir lewat rongga pori. Pori-pori tanah saling berhubungan antara satu dengan yang lainnya, sehigga air dapat mengalir dari titik tinggi energi yang lebih rendah. Untuk tanah permebilitas dilukiskan sebagai sifat tanah yang mengalirkan air melalui rongga pori. tanah

\section{Rembesan Pada Struktur}

\section{Bendungan}

Menurut Hardiyatmo HC (2012), Hukum Darcy dapat digunakan untuk menghitung debit rembesan yang melalui struktur bendungan. Dalam merencanakan sebuah bendungan, perlu diperhatikan stabilitasya terhadap bahaya longsoran, erosi lereng dan kehilangan air akibat rembesan yang melalui tubuh bendungan. Beberapa caradiberikan untuk menentukan besarnya rembesan yang melewati bendungan yang dibangun dari tanah homogennya. Dalam hal ini disajikan beberapa carauntuk menentukan debit rembesan.

a) Cara Dupuit

Potong melintang sebuah bendungan ditunjukkan gambar 1.Garis $\mathrm{AB}$ adalah garis freatis, yaitu garus rembesan paling atas. Besarnya rembesan persatuan lebar arah tegak lurus bidang gambar yang diberikan oleh Darcy, adalah $q=k i \mathrm{~A}$.

$Q \quad=k \frac{d z}{d x} \mathrm{Z}$ 


$$
\begin{aligned}
\int_{0}^{d} q d x & =\int_{h 2}^{h 1} k z \cdot d z \\
q & =\frac{k}{d x}\left(H 1^{2}-H 2^{2}\right)
\end{aligned}
$$

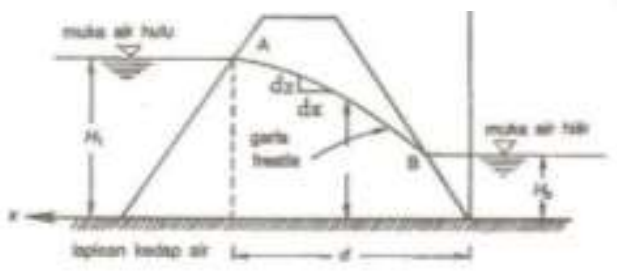

Gambar 1. Perhitungan Metode Dupuit

b) Cara Schaffernak

Untuk menghitung, Schaffernak (1917) dalam Hardiyatmo HC (2012), menganggap bahwa permukaan freatis akan merupakan garis $\mathrm{AB}$ dalam gambar 8, yang memotong garis kemiringan hilir pada jarak dari dasar lapisan kedap air. Rembesan persatuan panjang bendungan dapat ditentukan dengan memperhatikan bentuk segitiga BCD dalam gambar 2. $\mathrm{q}=\mathrm{kz} \frac{\mathrm{dz}}{\mathrm{dx}} \mathrm{k}$ a $\sin \alpha \operatorname{tg} \alpha \ldots \ldots(2)$

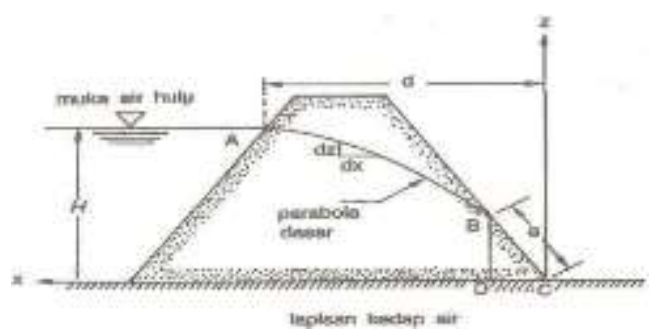

Gambar 2. Perhitungan Metode Schaffernak

c) Cara Cassagrande $\begin{array}{lcr}\text { Cassagrande } & \text { (1937) } & \text { dalam } \\ \text { Hardiyatmo } & \text { HC } & \text { (2012), } \\ \text { mengusulkan } & \text { cara } & \text { untuk }\end{array}$ menghitung rembesan lewat tubuh bendungan yang didasarkan pada pengujian model. Besarnya debit rembesan dapat ditentukan dengan: $\mathrm{Q}=\mathrm{kz} \frac{\mathrm{dz}}{\mathrm{dx}} \mathrm{z}=\mathrm{a} \sin ^{2} \alpha$

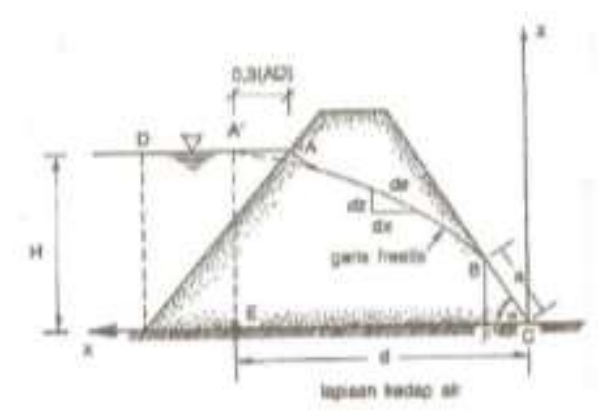

Gambar 3. Perhitungan Metode Cassagrande.

\section{Filter pada Bendungan}

Menurut Hardiyatmo HC (2012), bila air rembesan mengalir dari lapisan berbutir lebih halus menuju lapisan yang lebih kasar, kemungkinan terangkutnya butiran lebih halus lolos melewati bahan yang lebih kasar tersebut dapat terjadi. Erosi butiran ini mengakibatkan turunnya tahanan aliran air dan naiknya gradien hidrolik. Bila kecepatan aliran membesar akibat dari pengurangan tahanan aliran yang berangsur-angsur turun, akan terjadi erosi butiran yang lebih besar lagi, sehingga membentuk 
pipa-pipa di dalam tanah yang dapat mengakibatkan keruntuhan pada bendungan.

\section{Keamanan Terhadap Bahaya} Piping dan Boiling

Menurut Hardiyatmo HC (2012), telah disebutkan bahwa bila tekanan rembesan ke atas yang terjadi dalam tanah sama dengan $i_{c}$, maka tanah akan pada kondisi mengapung. Keadaan semacam ini juga dapat berakibat terangkutnya butir butir halus, sehingga terjadi pipa-pipa di dalam tanah yang disebut piping. Akibat jerjadinya pipa-pipa yang membentuk rongga-rongga dapat mengakibatkan pondasi bangunan mengalami penurunan.

Sedangkan pada boiling adalah kondisi yang terjadi pada saat tegangan efektiftanah sama dengan nol. Untuk mengatasi perlu dianalisis besarnya safety factor minimal yang dibutuhkan oleh owner agar bendungan tetap aman terhadap boiling $\leq 1,5$.

\section{Tekanan Hidrostatis}

Menurut Hardiyatmo HC (2006) dalam Jurnal Ariany dan Soehoed, Y.D.M (2012), tekanan hidrostatis adalah tekanan yang bergantung pada kedalaman terhadap suatu luas bidang tekan pada kedalaman tertentu. Besarnya tekanan ini bergantung pada ketinggian zat cair, massa jenis dan percepatan gravitasi. Tekanan yang dirasakan oleh dasar wadah yang berisi air sama dengan besarnya gaya berat zat cair yang menekan.

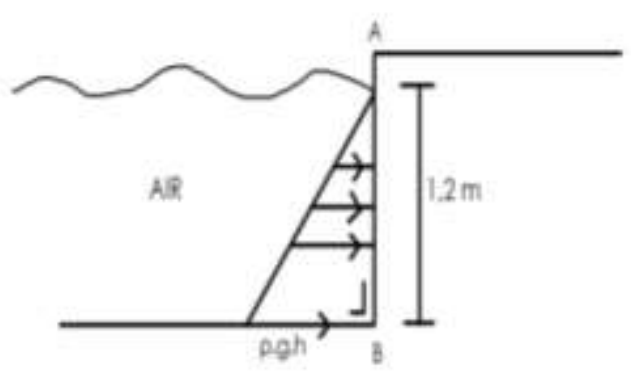

Gambar 4. Tekanan Hidrostatis

Pola Rembesan

Menurut Fukuda dan Tutsui (1973), dalam jurnal Adam Surya Praja, menyatakan bahwa perembesan air dapat terjadi di dalam tubuh tanggul, baik secara lateral (seepage) dan secara vertikal (perkolasi), yang dipengaruhi oleh permeabilitas, porositas, tekstur, kedalaman pori, kelembaban dan muka air tanah. Perkiraan rembesan penting dalam pembangunan bendungan baik jenis urugan termasuk tanggul, maupun beton.

menurut Hardiyatmo (1992), garis aliran berpotongan tegak lurus dengan 
garis ekuipotensial membentuk jaringan yang jumlahnya dinyatakan dengan Nf. Dua buah garis ekuipotensial membentuk interval $(\Delta \mathrm{h})$ dengan jumlah tertentu yang dinotasikan dengan $\mathrm{Nd}$.

\section{METODE PENELITIAN}

\section{Waktu dan Tempat Penelitian}

Penelitian ini dilaksanakan di Laborotorium Fakultas Teknik Universitas Muhammadiyah Makassar dengan waktu pengujian selama 2 bulan, apabila diakumulasikan penelitian ini selama 12 bulan mulai dari Juli - Mei 2017.

\section{Jenis Penelitian dan Sumber Data}

Jenis penelitian yang digunakan adalah uji simulasi, dimana kondisi tersebut dibuat dan diatur oleh peneliti, dengan tujuan untuk menyelidiki ada tidaknya hubungan sebab akibat serta berapa besar hubungan sebab akibat tersebut dengan cara memeberikan perbandingan antara beragam macam bahan bendungan (tanah) terhadap daya rembesan.

\section{Langkah - langkah Pengujian}

1. Prosedur penyiapan sampel
1) Pengadaan bahan pengujian meliputi tanah, air.

2) Persiapan peralatan pengujian yaitu kotak model.

3) Pemilihan air yang digunakan pada pengujian.

2. Prosedur pengujian model

1) Setting alat model dan melakukan running kosong

2) Material pembentuk tubuh bendungan sebelum dipadatkan, diayak terlebih dahulu dengan menggunakan saringan no 8.

3) Pada saat pembentukan model bendungan tanah dipadatkan dengan menggunakan balok kayu. Tanah dipadatkan perlapisan $(10 \mathrm{~cm}$ perlapisan) dengan jumlah tumbukan yang tetap. Tanah ditimbun membentuk trapezium dengan lebar puncak bendungan $5 \mathrm{~cm}$, panjang $72 \mathrm{~cm}$ dan tinggi 28 $\mathrm{cm}$.

4) Air diisi pada bagian hulu tubuh bendungan sebagai daerah genangan dengan tinggi muka air 10, 15 dan maksimum 20 $\mathrm{cm}$.

5) Setelah membentuk sebuah garis rembesan, kemudian di 
garis dengan menggunakan spidol pada dinding model, dan menghitung waktu rembesan disetiap selang.Observasi dilakukan sebanyak 3 kali dengan tinggi air tampungan secara bervariasi yaitu: 10, 15 dan $20 \mathrm{~cm}$.

6) Pengambilan data dilakukan sebanyak 3 kali dengan berbagai variasi tinggi muka air.

Skema kerja penelitian ini dapat dilihat pada gambar berikut:

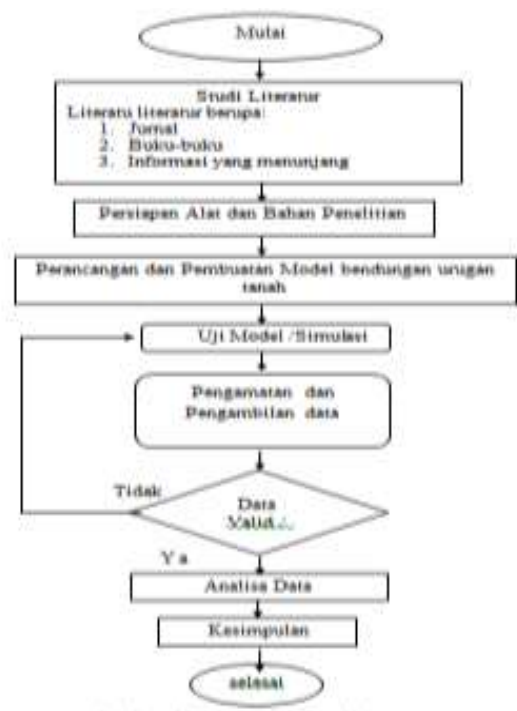

Gambar. 6. Bagan Alir Penelitian

\section{Hasil dan Pembahasan}

Tabel 1. Hasil rata-rata waktu rembesan dan jarak rembesan pada bendungan yang berbagai variasi muka air.

\begin{tabular}{ccccccc}
\hline & \multicolumn{3}{c}{$\begin{array}{c}\text { Waicu Rembesan (t) } \\
\text { Ment }\end{array}$} & \multicolumn{4}{c}{$\begin{array}{c}\text { Jakik Renbesan } \\
\text { (on) }\end{array}$} \\
\cline { 2 - 7 } & $H 10$ & $H 15$ & $H 20$ & $H 10$ & $H 15$ & $H 20$ \\
\hline 1 & 25,30 & 17,49 & 9,23 & 28 & 28 & 28 \\
\hline 2 & 19,2 & 7,32 & 6,00 & 38 & 38 & 38 \\
\hline 3 & 25,2 & 8,35 & 6,00 & 48 & 48 & 48 \\
\hline 4 & 34,2 & 10,08 & 5,47 & 58 & 58 & 58 \\
\hline 5 & 33,45 & 7,49 & 5,06 & 68 & 68 & 68
\end{tabular}

Sumber : Data Penelitian

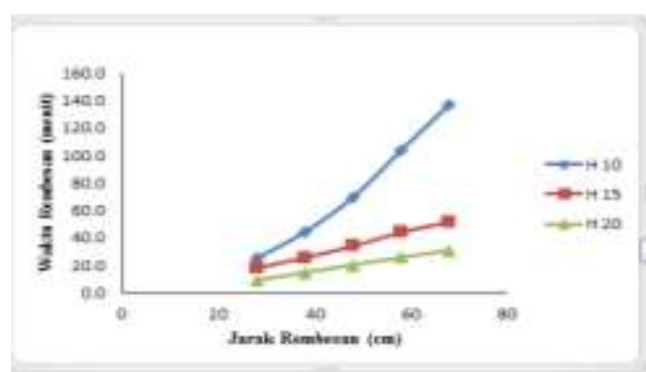

Gambar 7 . Hubungan Antara Jarak dan Waktu Rembesan

Pada gambar grafik di atas menunjukkan dimana untuk setiap pertambahan tinggi muka air maka nilai tekanan rembesan akan semakin meningkat. Dan semakin tinggi muka air di hulu bendungan (h) maka waktu rembesan semakin pendek, begitu pula sebaliknya semakin rendah tinggi muka airn maka akan semakin panjang pula waktu rembesan yang akan terjadi. Jadi pola rembesan pada gambar 16 bisa disimpulkan bahwa, semakin tinggi muka air di hulu bendungan maka akan semakin banyak pula zona basah yang di hasilkan. 
Tabel 2. Tekanan Rembesan dan Jarak Rembesan dengan Variasi Tinggi Muka Air

\begin{tabular}{cccccc}
\hline \multicolumn{2}{c}{ Bendung H10 } & \multicolumn{2}{c}{ Bendungan H15 } & \multicolumn{2}{c}{ Bendungan H20 } \\
\hline $\begin{array}{c}\text { Kedalaman } \\
\text { on }\end{array}$ & Jarak & Kedalaman & Jarak & Kedalaman & Jarak \\
\hline 10 & 12 & 15 & 18 & 20 & 24 \\
\hline 7 & 28 & 11 & 28 & 14 & 28 \\
\hline 6 & 38 & 10 & 38 & 13 & 38 \\
\hline 6 & 48 & 8,4 & 48 & 10 & 48 \\
\hline 5 & 58 & 8 & 58 & 8,7 & 58 \\
\hline 3,3 & 68 & 5,6 & 68 & 6,7 & 68 \\
\hline
\end{tabular}

Sumber : Pengelolah Data,2016

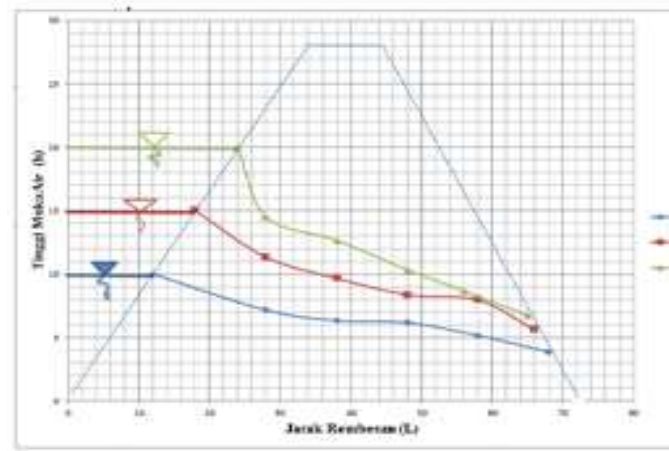

Gambar 8 . Hubungan Rata-rata pada Kedalaman Rembesan dan Jarak Rembesan

Pada gambar grafik 8 menunjukkan dimana untuk setiap pertambahan tinggi muka air maka nilai tekanan rembesan akan semakin meningkat. Dan semakin tinggi muka air di hulu bendungan (h) maka maka semakin pendek pula waktu yang dibutuhkan untuk merembes, itu disebabkan karena adnya tekanan hidrostatis. Semakin kecil tekanan hidrostatis semakin pada bagian hulu bendungan maka panjang pula waktu yang diperlukan untuk merembes.

Tabel 3. Hasil Perhitungan Debit Rembesan Metode Dupuit

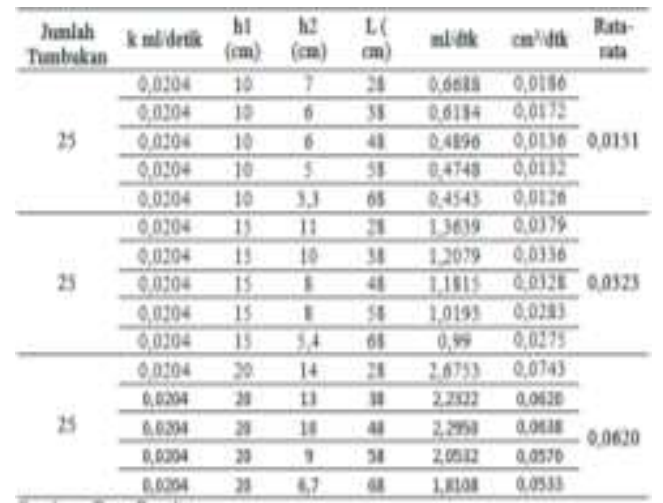

Sumber: Pengelolah Data,2016

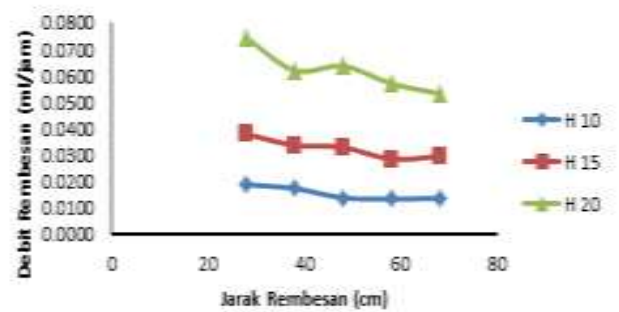

Gambar 9. Hubungan Antara Jarak Rembesan dan Debit Rembesan Metode Dupuit

Dari gambar dapat disimpulkan bahwa semakin jauh jarak rembesan maka akan semakin rendah pula rembesan yang terjadi. Jika jarak rembesan $(68 \mathrm{~cm})$ dan tinggi muka di hulu bendunga yaitu, $(10 \mathrm{~cm})$ maka akan trjadi debit rembesan $(0,4543$ $\mathrm{ml} / \mathrm{jam})$, dan apabila tinggi muka air di hulu $(15 \mathrm{~cm})$ dan jarak rembesan $(68 \mathrm{~cm})$ maka debit rembesan yang terjadi $(0,99 \mathrm{ml} / \mathrm{jam})$, sedangkan pada ketinggian $(20 \mathrm{~cm})$ dan jarak rembesannya $(68 \mathrm{~cm})$ maka debit rembesan yang terjadi yaitu, $(1,8108$ $\mathrm{ml} / \mathrm{jam})$.

Tabel 4. Hasil perhitungan debit 
rembesan metode Schaffernak

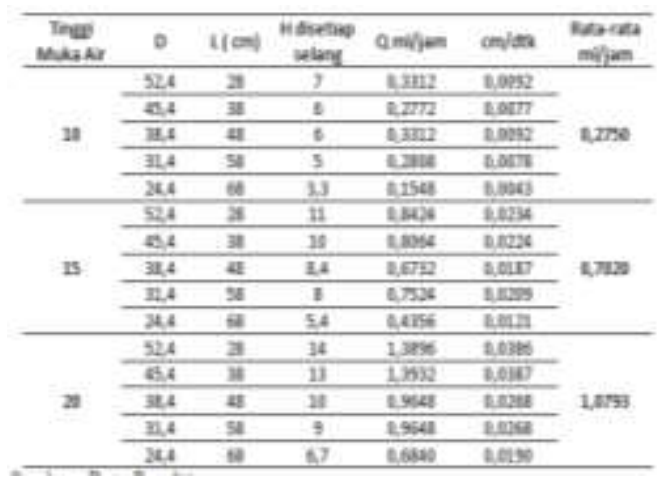

Sumber : Pengelolah Data,2016

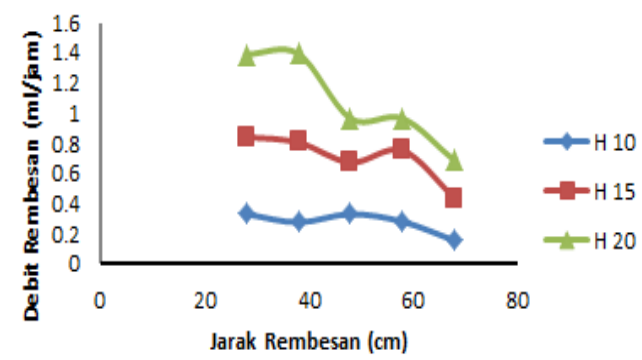

Gambar 10 . Hubungan Antara Jarak Rembesan dan Debit Rembesan Metode Schaffernak

Dari gambar disimpulkan bahwa semakin jauh jarak rembesan maka akan semakin rendah pula rembesan yang terjadi. Jika jarak rembesan $(68$ $\mathrm{cm})$ dan tinggi muka di hulu bendunga yaitu, $(10 \mathrm{~cm})$ maka akan trjadi debit rembesan $(0,1548$ $\mathrm{ml} / \mathrm{jam}$ ), dan apabila tinggi muka air di hulu $(15 \mathrm{~cm})$ dan jarak rembesan $(68 \mathrm{~cm})$ maka debit rembesan yang terjadi $(0,4356 \mathrm{ml} / \mathrm{jam})$, sedangkan pada ketinggian $(20 \mathrm{~cm})$ dan jarak rembesannya $(68 \mathrm{~cm})$ maka debit rembesan yang terjadi yaitu, $(0,6840$ $\mathrm{ml} / \mathrm{jam})$.

Tabel 5. Hasil Perhitungan Debit Rembesan Metode Cassagrande

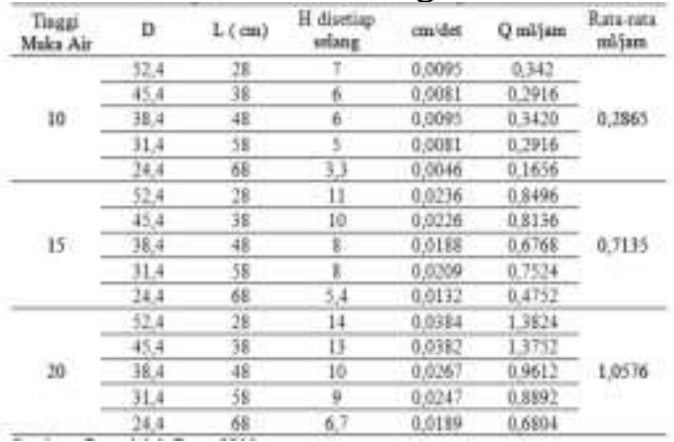

Sumber : Pengelolah Data, 2016

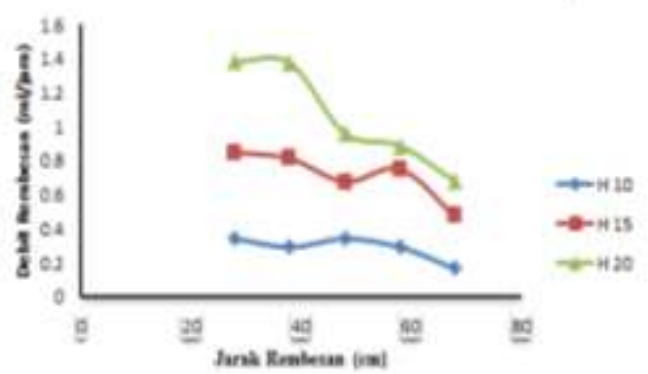

Gambar 11. Hubungan Antara

Tinggi Hidrostatis dan Debit Rembesan Metode Cassagrande.

Dari gambar 11 dapat disimpulkan bahwa semakin tinggi tekanan hidrostatis maka akan semakin besar debit rembesan. Untuk tekanan hidrostatis $\mathrm{H}_{10}$ debit rembesannya sebesar 0,2865 $\mathrm{ml} / \mathrm{jam}$, tekanan hidrostatis $\mathrm{H}_{15}$ debit rembesannya sebesar $0,7135 \mathrm{ml} / \mathrm{jam}$, dan tekanan hidrostatis $\mathrm{H}_{20}$ debit rembesannya sebesar $1,0576 \mathrm{ml} / \mathrm{jam}$. 


\section{PENUTUP}

\section{Kesimpulan}

Berdasarkan hasil penelitian yang telah dilaksanakan, maka dapat disimpulkan bahwa:

1) Dari hasil pengamatan langsung dapat disimpulkan bahwa pola rembesan yang terjadi pada setiap variasi hidrostatis itu berbedabeda, disebabkan karena tekanan hidrostatis yang mempengaruhi kecepatan rembesan. Semakin tinggi tekanan hidrostatis pada bendungan maka akan semakin pendek waktu yang dibutuhkan untuk merembes.

2) Dari hasil perhitungan debit rembesan dengan tiga metode yaitu, metode Dupuit, Schaffernak dan Cassagrande. Pada metode Cassagrande memperlihatkan debit yang tertinggi untuk $\mathrm{H}_{10}$ dan $\mathrm{H}_{15}$. Sedangkan pada tinggi hidrostatis $\mathrm{H}_{20} \quad$ Metode $\quad$ Schaffernak memperlihatkan debit yang tertinggi.

\section{Saran}

Dari pengamatan di dalam Penelitian ini penulis memberikan saran-saran untuk penelitian lebih lanjut, yaitu :
1) Penelitian tentang pengaruh rembesan pada tubuh bendungan urugan perlu dikembangkan dengan variasi kepadatan tanah dan jenis tanah yang digunakan.

2) Penelitian tentang rembesaan pada bendungan urugan tanah ini perlu dikembangkan lagi dengan jenis tanah yang digunakan pada setiap model bendungan.

\section{DAFTAR PUSTAKA}

Asianto. 2011. Metode Konstruksi Bendungan, Penerbit Universitas Indonesia UI Press,Jakarta.

Aryani dan Soehoed Y.D.M (2012), Tinjauan Tinggi tekanan Air dan Rembesan pada Bendungan Menggunakan Alat Peraga Bendung Tanpa Turap. Majalah Ilmiah UKRIM Edisi 1/th XVII/2012. Jurusan Teknik Sipil Universitas Keristen Ianuemml Yogyakarta.

Hardiyatmo, Hary C. 2012. Mekanika Tanah 1, ,Penerbit Gadjah Mada University Press, Yogyakarta

Husni Sabar, 2013 Waduk Dan Tenaga Air, Penerbit ITB Institut Teknologi Bandung

Muchammad Ilham , 2015). Analisa stabilitas tubuh bendungan pada bendungan utama tugu kabupaten trenggalek.Universitas Brawijaya 
Jurnal Teknik Hidro

Vol. 11 No. 1, Februari 2018

Neogroho Djarwanti, 2008.

Komparasi Koefisien

Permebilitas (k) Pada Tanah

Kohesif, FT UNS

Panguriseng Darwis, Mekanika

Tanah 1. Bahan Ajar Mata Kuliah 2013.

Prasetyo siagian dan N. Suharta 2012 Permebilitas Tanah, Artikel ( diakses pada 19 november 2016).

Sukirman, 2014. Analisis Rembesan Pada Bendung Tipe Urugan

Melalui Uji Hidrolik, Jurnal Teknik Sipil dan Lingkungan Vol. 2, No. 2, Juni $2014 \quad \mathrm{di}$ Laboratorium Hidro FT UNSRI, Universitas Sriwijaya.

Sosrodarsono, Suyono. Ir. 1977. Bendungan type Urugan. P.T Pradnya Paramita. Jakarta. 